\title{
Fire and plant diversity at the global scale
}

\author{
${ }^{1}$ Centro de Investigaciones sobre \\ Desertificaciōn, Consejo Superior de \\ Investigaciones Científicas (CIDE-CSIC), \\ Ctra. Naquera Km. 4.5 (IVIA), Montcada, \\ Valencia 46113 , Spain \\ ${ }^{2}$ International Soil Reference and \\ Information Centre (ISRIC) - World Soil \\ Information, Wageningen, The Netherlands \\ Correspondence \\ Juli G. Pausas, CIDE-CSIC, Ctra. Naquera \\ Km. 4.5 (IVIA), Montcada, Valencia 46113 , \\ Spain. \\ Email: juli.g.pausas@ext.uv.es \\ Funding information \\ FILAS project from the Spanish government \\ (Ministerio de Economía y Competitividad), \\ Grant Number: CGL2015-64086-P; \\ Valencia government (Generalitat \\ Valenciana), Grant Number: PROMETEO/ \\ 2016/021
}

\section{Juli G. Pausas ${ }^{1}$ \& Eloi Ribeiro ${ }^{2}$}

\begin{abstract}
Aim: Understanding the drivers of global diversity has challenged ecologists for decades. Drivers related to the environment, productivity and heterogeneity are considered primary factors, whereas disturbance has received less attention. Given that fire is a global factor that has been affecting many regions around the world over geological time scales, we hypothesize that the fire regime should explain a significantproportion ofglobal coarse-scaleplantdiversity.
\end{abstract}

Location: All terrestrial ecosystems, excluding Antarctica.

Time period: Data collected throughout the late 20th and early 21st century.

Taxa: Seed plants (5 spermatophytes 5 phanerogamae).

Methods: We used available global plant diversity information at the ecoregion scale and com- piled productivity, heterogeneity and fire information for each ecoregion using 15 years of remotely sensed data. We regressed plant diversity against environmental variables; thereafter, we tested whether fire activity still explained a significant proportion of the variance.

Results: Ecoregional plant diversity was positively related to both productivity $\left(R^{2} 5.30\right)$ and fire activity $\left(R^{2} 5\right.$.38). Once productivity and other environmental variables were in the model $\left(R^{2} 5.50\right)$, fire regime still explained a significant proportion of the variability in plant diversity (overall model, $R^{2} 5$ .71). The results suggest that fire drives temporal and spatial variability in many ecosystems, providing opportunities for a diversity of plants.

Main conclusions: Fire regime is a primary factor explaining plant diversity around the globe, even after accounting for productivity. Fires delay competitive exclusion, increase landscape heter- ogeneity and generate new niches; thus, they provide opportunities for a large variety of species. Consequently, fire regime should be considered in order to understand global ecosystem distribu- tion and diversity.

\section{KEYWORDS}

diversity, fire regime, plant richness, productivity, pyrogeography

\section{INTRODUCTION}

Understanding the factors determining species diversity is of prime importance in ecology. Many factors may play a role in determining species diversity (e.g., environmental characteristics, historical factors, heterogeneity, disturbance regime, species interactions), and the pattern and importance of each one depends on the scale (Rosenzweig, 1995), For instance, there is an extensive literature suggesting that productivity is a major driver of diversity. At the local scale, that is, at the scale at which species interaction is a dominant process (small plots), a humped relationship between diversity and productivity is likely, because competitive exclusion limits the species at high productivity (Fraser, Pither, \& Jentsch, 2015; Grime, 1973, 1979), although this pattern can be relatively weak (Tredennick, Adler, \& Grace, 2016) and driven by a variety of processes (Grace, Anderson, \& Seabloom, 2016). However, when diversity is considered at a large biogeographical scale (meaning coarse grain and among regions), a clear positive linear relationship is the rule (Coleman, Mares, Willig, \& Hsieh, 1982; Gillman \& Wright, 2006; Gillman et al., 2015; O'Brien, 2006; Rosenzweig, 1995). This positive relationship between productivity and richness at large 
scales is typically explained by the crossing of different species pools and by the higher energy and the greater rate of speciation in high productivity environments (Gillman \& Wright, 2006); richness can also promote productivity and contribute to this relationship (Grace et al., 2016; Naeem, Thompson, Lawler, Lawton, \& Woodfin, 1994).

Disturbance is another major driver of diversity (Connell, 1978; Huston, 1979, 2014). At the local scale, disturbance delays competitive exclusion and thus increases the opportunity for different species to occur. However, very high (mortality-causing) disturbance may limit many species from entering into the community, thus the intermediate disturbance hypothesis is the prevalent expectation, perhaps since Loucks (1970). However, a large variety of relationships has been observed, depending mainly on the scale, type and severity of disturbance, among other factors (Mackey \& Currie, 2001).

At the geographical scale, it is likely that the diversity-disturbance relationship depends on the type of disturbance and its history, because a disturbance with a long evolutionary history would have selected for a variety of species able to persist that disturbance. For instance, fire is a disturbance with a very long evolutionary history (Pausas \& Keeley, 2009), and recurrent fires have selected for specific plant persistence traits (Keeley, Pausas, Rundel, Bond, \& Bradstock, 2011 , 2012). Indeed, there is microevolutionary evidence suggesting that fire can drive phenotypic and genetic divergence within species (Go̊mez-Gonzălez, Torres-Díaz, Bustos-Schindler, \& Gianoli, 2011; Hernåndez-Serrano, Verdū, Gonzålez-Martínez, \& Pausas, 2013; Pausas 2015a; Pausas, Alessio, Moreira, \& Corcobado, 2012; Vandvik et al., 2014). Likewise, macroevolutionary studies show the importance of fire in the diversification of some plant lineages (Bytebier, Antonelli, Bellstedt, \& Linder, 2011; Crisp, Burrows, Cook, Thornhill, \& Bowman, 2011 ; He, Lamont, \& Downes, 2011 ; He, Pausas, Belcher, Schwilk, \& Lamont, 2012). Consequently, higher fire frequency does not equal higher mortality, and thus the decrease in diversity at the high end of the disturbance gradient (i.e., the intermediate disturbance hypothesis; Huston, 2014) is unlikely in fire-prone ecosystems. In addition, fires generate landscape mosaics where different species are at an optimum at different times after a disturbance event (Cohn, Di Stefano, Christie, Cheers, \& York, 2015; Farnsworth, Nimmo, Kelly, Bennett, \& Clarke, 2014). It is now well accepted that fire affects most regions worldwide (although with different regimes) and has structured many communities and biomes (Bond, Woodward, \& Midgley, 2005; Krawchuk, Moritz, Parisien, Van Dorn, \& Hayhoe, 2009; Pausas \& Keeley, 2009; Pausas \& Ribeiro, 2013; Verdủ \& Pausas, 2007). Thus, fire is likely to be a major driver of plant diversity (Sauquet et al., 2009); however, most research on plant diversity at a large scale has focused on other parameters (e.g., climate, productivity, heterogeneity; Francis \& Currie, 2003; Hawkins et al., 2003; Kreft \&Jetz, 2007; O’Brien, 2006). Fire could well be the driver that opens opportunities in many regions, even in high productivity regions (e.g. Charles-Dominique, Beckett, Midgley, \& Bond, 2015). Despite the fact that both productivity and fire are supposed to be major drivers of diversity, the relative role of each remains to be explored in detail (Huston, 2014; Burkle, Myers, \&Belote, 2015). Iffire is an important driver for the distribution of ecosystems (Bond et al.,
2005; Dantas, Hirota, Oliveira, \& Pausas, 2016 ; Keeley \& Rundel, 2005), it is likely to determine large-scale diversity patterns.

Our hypothesis is that the fire regime should explain a significant proportion of the global coarse-scale plant diversity, even after accounting for productivity. In addition to productivity and disturbance, another major driver of diversity when working with coarse-grain units is the heterogeneity of the spatial unit (Pausas, Carreras, Ferre̊, \& Font, 2003; Rahbek \& Graves, 2001; Ricklefs, 1987; Stein, Gerstner, \& Kreft, 2014), and so this parameter needs to be considered in any coarsegrain study. To test our hypothesis, we use available global plant diversity information for world ecoregions and compile productivity, heterogeneity and fire information for each ecoregion using 15 years of remotely sensed data. We do not expect to find a decreasing pattern of diversity either at high fire activity (i.e., intermediate disturbance hypothesis) or at high productivity (i.e., intermediate productivity hypothesis). As mentioned above, this is because of (a) the coarse grain of our spatial unit (ecoregions), (b) the fact that our global gradient cross different species pools, and (c) the fact that high fire activity does not necessarilyimply high mortality.

\section{METHODS}

\subsection{Spatial unit}

Our study units are the terrestrial ecoregions proposed by the World Wildlife Fund (WWF; Olson, Dinerstein, \& Wikramanayake, 2001). A terrestrial ecoregion is defined as a relatively large unit of land containing a distinct assemblage of natural communities sharing a large majority of species, dynamics and environmental conditions. These ecoregions represent the original distribution of distinct assemblages of species and communities (Olson et al., 2001). Ecoregions are a promising way to structure ecological and fire information at a global scale because they are relatively homogeneous in climate and vegetation, and so the within/between variability ratio and spatial autocorrelation are both minimized in the main fire regime drivers (Pausas \& Ribeiro, 2013). Thus, ecoregions should be a more ecologically based way of aggregating biological information than arbitrary grid units. The original WWF map included 827 ecoregions distributed in 14 biomes. We exclude ecoregions that lack burnable vegetation, such as those in Antarctica and those dominated by rocks, ice and lakes, and ecoregions where we did not have all the predictor variables (several small ecoregions). The final number of ecoregions considered was 753 , distributed in 14 biomes and accounting for $88.3 \%$ of terrestrial land.

\subsection{Data}

Plant species richness for each ecoregion was obtained from Kier et al. (2005). This represents a major effort in compiling vascular plant species richness for all the world's ecoregions. The data were obtained from many sources; the suitability and quality of the data for each ecoregion was rated from 1 (best quality) to 4 (poorest) by the compilers. The estimated richness also includes some uncertainty, with a minimum and a maximum estimate value for each ecoregion, in 
addition to the main estimate. Another global source of plant information is the Global Biodiversity Information Facility (GBIF), which is a huge effort to compile localities for all world's species. We downloaded (GBIF.org, 18 April 2016) the records of spermatophytes (phanerogamae) that had geographical coordinates (fossil records excluded), corrected synonyms and crossed the coordinates with the ecoregion map. This provides 109,140,607 plant records with correct data for the 753 ecoregions considered (median 57,040 records/ecoregion), from which we counted the number of species in each ecoregion. This data set includes aliens, as GBIF does not categorize records by their origin.

Information on the productivity, heterogeneity and temporal variability of each ecoregion was obtained from the mean and variability of remotely sensed normalized difference vegetation index (NDVI). The relationship between NDVI and vegetation variability and productivity is well established (Pettorelli et al., 2005). Specifically, we used 16-day global NDVI images (resolution 50.058) from Febrary 2000 to July 2015 (355 global images; MODIS MOD13C1 data set obtained from the Land Processes Distributed Active Archive Center, USCS). Each image was crossed with the ecoregion map, and for each ecoregion, we extracted the mean and the SD of the NDVI (i.e., mean and heterogeneity). These two values were averaged across the whole period to obtain a mean NDVI value (productivity) and a mean spatial variability (heterogeneity) for each ecoregion (hereafter, mean NDVI and spatial NDVI variability). In addition, the 355 NDVI values for each ecoregion were treated as a time series and decomposed into seasonality and trend (using the stats package of R); the SD of the trend (across the entire period) was used as an indicator of the temporal variability (hereafter, temporal NDVI variability). The same process was performed with the enhanced vegetation index (EVI); however, given the high correlation between both indexes at the ecoregion scale ( $r 5.964)$, all subsequent analyses were performed with NDVI only.

Additionally, to account for spatial and environmental variability among ecoregions, we also considered the climatic information provided by the WorldClim (Hijmans, Cameron, Parra, Jones, \& Jarvis, 2005). Each WorldClim map (resolution 530 s, i.e., 0.0088) was crossed with an ecoregion map to compute the mean value for each ecoregion.

An indicator of the fire regime of each ecoregion was obtained from MODIS hotspots (Collection 5 Active Fire Products; Giglio, 2013). Specifically, we used the monthly hotspots from the Terra satellite as compiled in the Clima Modelling Grid at 0.58 of resolution (MOD14CMH; data set downloaded from the University of Maryland, U.S.A.) for the period from November 2000 to August 2015 (182 images). Each image was crossed with the ecoregion map to obtain the number of hotspots (cloud-corrected fire pixels) and the mean radiative power in each ecoregion and month. For each ecoregion, monthly data were averaged across the entire period. Then, the fire regime of each region was approximated on the basis of two variables, fire activity and radiative power. Fire activity was computed as the logarithm of the ratio between the average number of hotspots (active fires) and the ecoregion area, and then rescaled from 0 to 1 (Pausas \& Ribeiro, 2013); this value is a good indicator of the observed fire activity in the field (see validation exercise in Pausas \& Ribeiro, 2013). Radiative power was defined as the mean radiative power of each ecoregion over the 15-year period (Kaufman et al., 1988; Wooster, Zhukov, \& Oertel, 2003). The two variables (fire activity and radiative power) are somewhat correlated ( $r 5.68$ ), probably because high radiative power can be produced by a high density of hotspots. Ecoregions with no fire during the time period were considered to have fire activity and radiative power equal to 0 .

MODIS hotspots refer to recent fire regime (2000-15); however, they are a good indicator of the flammability or fire-proneness of a region; that is, despite fire regimes being strongly influenced by human activities (increasing and decreasing fire activity in different ecosystems; Bowman et al., 2011 ; Marlon et al., 2008; Pausas \& Keeley, $2009,2014)$, at the global scale and among regions, there is a significant proportion of the variability that is explained by non-human factors, such as climate, productivity and vegetation structure (e.g., Archibald, Lehmann, Go̊mez-Dans, \& Bradstock, 2013; Parisien \& Moritz, 2009; Pausas \& Keeley, 2009; Pausas \& Ribeiro, 2014). In fact, even for a given region with a given human impact, temporal variations in fire activity are strongly influenced by changes in weather and climatic conditions (e.g., Littell, McKenzie, Peterson, \& Westerling, 2009; Parisien \& Moritz, 2009; Pausas \& Paula, 2012).

\subsection{Analysis}

Plant diversity was estimated as the logarithm of the ratio between the number of species in each ecoregion and the ecoregion area (in kilometres squared). Plant diversity for each ecoregion obtained from Kier et al. (2005) was highly correlated with the diversity value obtained from GBIF records ( $F 51325$, d.f. $51,785, p<.00001, R_{\text {adj }}^{2} 5.63$ for all ecoregions; $F 5758.4$, d.f.51, 138, $p<.00001, R_{\text {adj }}^{2} 5.85$ for ecoregions with the highest data quality). Given this high correlation and that the data from GBIF produced slightly less species, and also given that the data set of Kier et al. (2005) is likely to be more homogeneous, we used this latter set formost of our analysis.

The plant diversity variable was normally distributed (Shapiro-Wilk test: $W 5.99, p 5.69)$. As a preliminary analysis, we first related plant diversity to fire activity using standard least-squares regressions, considering the three estimates of plant diversity (the main estimate, the minimum and the maximum). To discard a possible humped response, quadratic responses (diversity against the square of fire activity) were also tested. Plant diversity was then related to all the independent variables using mixed-effects models. Given that global plant diversity may have a component related to the different biogeographical histories among continents (e.g., Adams \& Woodward, 1989; Qian \& Ricklefs, 1999; Ricklefs, Latham, \& Qian, 1999), we used floristic realm (Australasia, Afrotropic, Indomalaya, Nearctic, Neotropic, Oceania and Palearctic) as a random factor in our analyses. Using this mixed-effects model approach, we fitted three set of models, as follows. (a) First, we fitted plant diversity against the following variables independently (i.e., univariate models): mean NDVI (productivity); spatial NDVI variability (heterogeneity); temporal NDVI variability; biome (14 classes; which may account for additional information not accounted by NDVI); climatic (WorldClim) variables; and fire variables (fire activity and radiative 
power). Of the climatic variables, seasonality in temperature was the most significant variable related to plant diversity, and for the sake of simplicity, this is the variable reported here. (b) We then built a mutlivariate fire model by including the two fire-related variables and their interactions. (c) We built a multivariate model to test whether fire regime was still significant once the other predictors were accounted for in the model. To do that, we first fitted the NDVI and climatic variables that significantly explained variability in plant diversity [step (a) above] and then tested whether fire activity, radiative power and the interaction still accounted for some unexplained variance (multivariate model). For the multivariate model, only variables that were highly significant $(p<.0001)$ were included. Models were fitted with the maximum log-likelihood approach, and the selection was based on the lowest Akaike information criterion (AIC) for models in which the likelihood ratio test was significant; we used the $n$ /me library in R (Pinheiro, Bates, DebRoy, Sarkar, \& R Core Team, 2016). In all the models, we used the quality of the plant diversity data provided by Kier et al. (2005) as regression weight (quality 1, 2, 3 and 4 were transformed as weights $1,0.8,0.6$ and 0.4 , respectively). The relationship between diversity and fire regime was also tested for the subset of the ecoregions with the highest quality (i.e., quality 51 ).

We evaluated the spatial autocorrelation (using Moran's / statistic) of the dependent variable and of the residual of the models fitted because geographically distributed data are prone to a high type I error (Legendre, 1993; Lennon, 2000). Strong spatial structure in the residuals would suggest that closely located ecoregions do not provide independent data points for testing long-distance effects, whereas a low autocorrelation of the residuals would imply that the regressions are unaffected by autocorrelation (Diniz-Filho, Bini, \& Hawkins, 2003). Spatial autocorrelograms were computed using NCF software (Bjornstad, 2009).

\section{RE SULTS}

Global distribution of plant diversity and fire activity is shown in Figure 1. Plant species diversity was positively related to fire activity
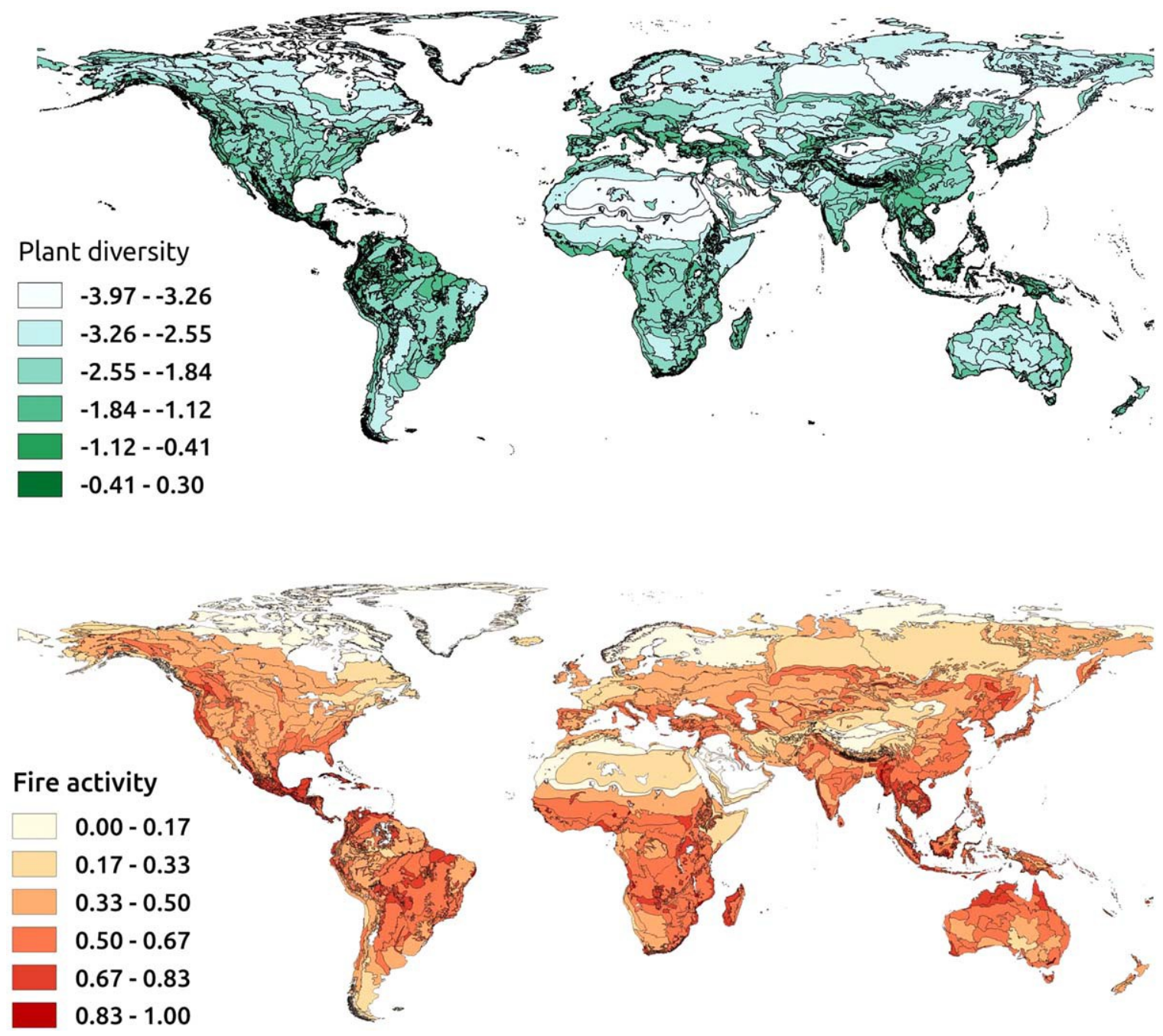

FIGURE 1 Global maps of the plant diversity and fire activity indices byecoregions. The intensity of the colours in each ecoregion is related to the plant diversity (above; logarithm of the number of species divided by the ecoregion area) and fire activity (below; from 0 to 1 ) 

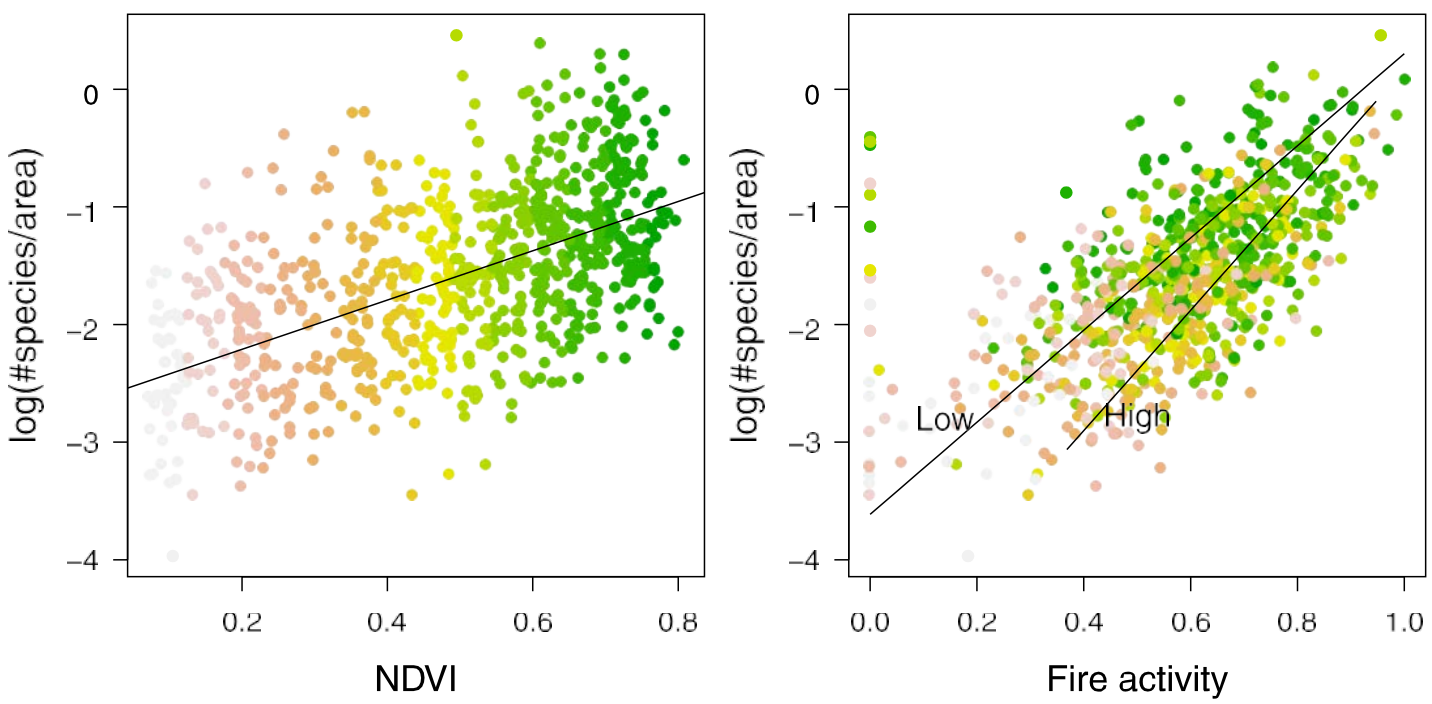

FIGURE 2 Plant diversity in each global ecoregion (the number of species divided by area, log scale) plotted against NDVI (left) and fire activity (right), and including fitted lines. The two lines for the fire activity graph (right) refer to fitted lines for low radiative power (quantile 0.25 , upper line) and high radiative power (quantile 0.75 , lower line). The colours of the symbols are related to the NDVIvalue of the ecoregion. For statistics, see Table 1. NDVI5 normalized difference vegetation index

when computing diversity using the estimated number of species $\left(R^{2} 5.38, p<.0001, n 5753\right)$, the minimum estimate $\left(R^{2} 5.34\right.$, $p<.0001)$ or the maximum $\left(R^{2} 5.41, p<.0001\right)$. A similar relationship was observed when only the highest quality diversity data were considered $\left(R^{2} 5.28, n 5130, p<.0001\right)$. The relationship between plant diversity and fire activity was also highly significant when using GBIF data $\left(R^{2} 5.22, p<.0001\right.$ for all ecoregions; $R^{2} 5.36$ for ecoregions with more than $0.1 \mathrm{record} / \mathrm{km}^{2}$ ). There was no evidence of a humpshaned relationshin (Figure ?)

When compared with alternative variables using the mixed-effects model, fire activity was the best sinqle predictor of plant species diversity (i.e., the most parsimonious model, with the lowest AIC; Table 1a), tolıowea py bıome, temperature seasonalıty (negatıve relatıonsnıp) and mean NDVI (positive relationship). Spatial and temporal variability of NDVI were also significant (positive and negative, respectively), with the former more important than the latter. For the fire model, the explained variance increased significantly when radiative power and interaction were added (Figure 2, Table $1 \mathrm{~b}$ ); the interaction between fire activity and radiative power suqqests that radiative power reduces plant diversity, especially in ecoregions with relatively low fire activity (Fiqure 2, Table 1b; distribution of residuals in Supporting Information Fiqure S1 a). When biome, seasonality and mean NDVI were included in

the diversity model, spatial and temporal NDVI variabilities were no longer significant, whereas fire activity, radiative power and the interaction still accounted for a significant proportion of the variability (Table 1c; distribution of residuals in Supporting Information FigureS1b).

Plant diversity and all predictor variables were spatially autocorrelated (Moran's / values ranging from 0.45 to 0.75 ). The fitted models successfully remove the spatialautocorrelation from the residuals $(I<.07$; Figure 3$)$, suggesting that a type $I$ error in our results was unlikely.
TABLE 1 A summary of the mixed models where the variability in global plant diversity (the number of species of each ecoregion divided by the area, log scale) was tested against a set of predictors

AIC LR $\quad p \quad$ Trend $R^{2}$

(a) Univariate models

$\begin{array}{lrrrrr}\text { Null } & 1,480.39 & & & & \\ \text { FA } & 1,208.83 & 273.56 & <.0001 & 1 & .38 \\ \text { Biome[14] } & 1,239.38 & 267.01 & <.0001 & & .39 \\ \text { Temperature seasonality } & 1,318.49 & 163.90 & <.0001 & 2 & .34 \\ \text { Mean NDVI } & 1,303.13 & 179.26 & <.0001 & 1 & .30 \\ \text { Spatial NDVI } & 1,439.14 & 43.25 & <.0001 & 1 & .12 \\ \text { Temporal NDVI } & 1,479.64 & 10.39 & .0013 & 2 & .07 \\ \text { RP } & 1,476.00 & 6.39 & .0115 & 1 & .04\end{array}$

(b) Multivariate model: fire

Null
FA
1 RP
1 FA 3 RP

$\begin{array}{rrrrr}1,480.39 & & & & \\ 1,208.83 & 273.56 & <.0001 & 1 & .38 \\ 1,075.49 & 135.34 & <.0001 & 2 & .46 \\ 970.00 & 107.49 & <.0001 & 1 & .54\end{array}$

(c) Multivariate model: full Null

$1,480.39$

Mean NDVI

$1,303.13 \quad 179.26<.0001 \quad 1 \quad .30$

1 Biome[14]

$1,176.61 \quad 152.52<.0001$

1 Temperature seasonality

$\perp$ LA

,145.62 $33.00<.00012$

1 RP

1 FA 3 RP

$840.83 \quad 100.42<.00012 \quad .65$

$680.52 \quad 162.31<.0001 \quad 1 \quad .71$

Note. Models include the floristic realm as a random factor, and the accuracy of the plant data as weight. The Akaike information criterion (AIC) and likelihood ratio test (LR) for each variable are shown, together with the sign of the coefficient (trend). For illustrative purposes, the last column provides the $R^{2}$ value of the corresponding standard linear model. Note that each variable is fitted independently in univariate models (a), but sequentially in multivariate models (b and c). For the mutivariate models, analysis of the residuals is provided in the Supporting Information. FA5 fire activity; RP5 radiative power; NDVI5normalized difference vegetation index; Bioma[14] refers to the 14 biomes defined by Olson et al. (2001). 


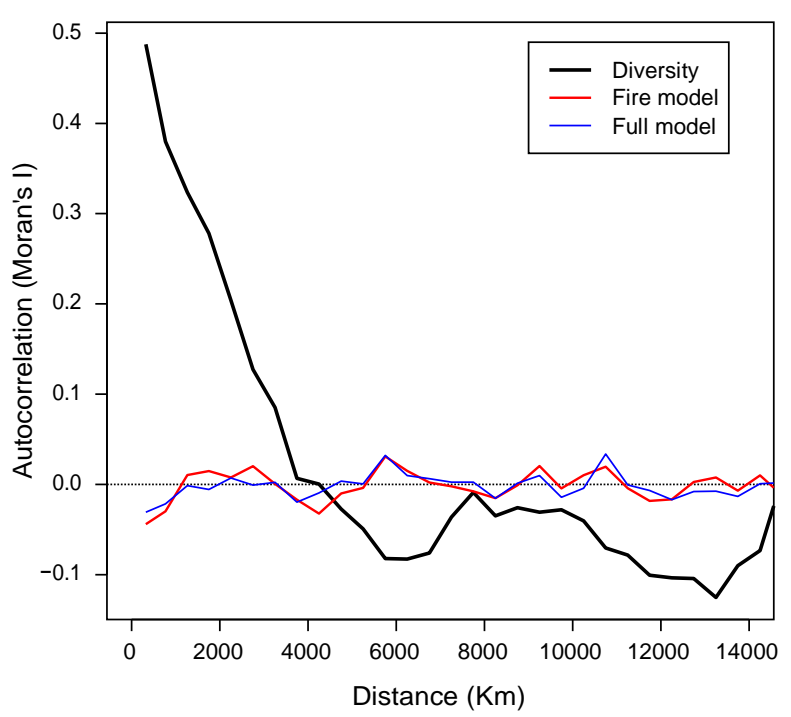

FIGURE 3 Spatial correlogram(Moran's / index) of plant diversity in each ecoregion (thicker black line) and the residuals of the fire and the full models (thinner lines; Table $1 \mathrm{~b}$ and c, respectively)

\section{DISCUSSION}

Productivity is a major driver of plant diversity. Diversity increases with productivity, as has been widely reported in the literature, especially when analysing large geographical units (e.g., Coleman et al., 1982; Gillman \& Wright, 2006; Gillman et al. 2015; O’Brien, 2006; Rosenzweig, 1995). The spatial heterogeneity of the geographical units (ecoregions) was also a significant predictor of plant diversity, as proposed in previous studies (Pausas et al., 2003; Stein et al., 2014). Temporal variability showed a negative relationship with diversity, which probably accounts for the well-known latitudinal gradient (Gillman et al., 2015; Rosenzweig, 1995). However, fire activity was the best single parameter accounting for variability in plant diversity (i.e., it was the variable that generated the largest reduction in AIC; Table 1a). Even after including major biodiversity drivers in the model (productivity, heterogeneity, seasonality and even biome), fire regime (i.e., fire activity, radiative power and the interaction) still accounted for a significant variability (Table 1c). In addition, the relationship is not humped (as predicted by the intermediate disturbance hypothesis), because of the large biogeographical scale of the study (coarse grain and among species pools) and the low fire mortality in fire-prone ecosystems. Consequently, at the global scale, disturbance and productivity are both important axes of plant diversity (Huston, 2014).

The accuracy of the global plant diversity data is certainly limited, but it was compiled independently of the fire information, and thus a bias with regard to fire regime is unlikely; a reanalysis with the subset of ecoregions that have the most accurate data does not change our result. Furthermore, the models are very similar (significant and with the same signs) if we use the plant diversity obtained from GBIF. Another limitation is that ecoregions are unlikely to be homogeneously defined across the globe, but it is probably the current best approach for an ecologically defined global map. Our approximation of fire regime also has limitations, especially the lack of a clear differentiation among different fire spread types (i.e., crown versus surface fires) and the clear meaning of the two fire regime variables at the coarse scale considered. Low radiative power is likely to reflect surface fires, although ecosystems with high activity of surface fires can generate high radiative power. The fact that radiative power reduces plant diversity in ecoregions with relatively low fire activity (Figure $2 b$ ) suggests that fire intensity might be playing a role in affecting plant diversity. Remotely sensed fire detection may be limited during periods and zones featuring very thick cloud cover and for understory and peat fires (Schroeder, Csiszar, \& Morisette, 2008), and may be poor in capturing small fires; data also account for a relatively short ( 15 years) temporal window. However, despite all these limitations, our results show a clear pattern, suggesting that fire regime is a strong predictor of coarse-scale global plant diversity.

There are at least two (not mutually exclusive) mechanisms by which fire may drive plant diversity at the scale and grain considered here. The first is a selective process, as there is both micro- and macroevolutionary evidence suggesting that fire regime can drive population divergence and diversification (Bytebier et al., 2011; Crisp et al., 2011; Go̊mez-Gonzălez et al., 2011; He et al., 2011, 2012; HernăndezSerrano et al., 2013; Pausas, 2015 a; Pausas et al., 2012; Vandvik et al., 2014). The second process suggests that fire generates landscape mosaics and thus more habitat types and more niches likely to be filled by different species (e.g., Bird, Bird, Codding, Parker, \& Jones, 2008; Bond \& Keeley, 2005; Cohn et al., 2015; Kelly et al., 2012; Parr \& Brockett, 1999); in this sense, fire would generate the biotic heterogeneity that drives diversity (Stein et al., 2014), as proposed by the 'pyrodiversity begets diversity' hypothesis (Bowman et al., 2016; Martin \& Sapsis, 1992). The fire-driven alternative states in a given climate are a clear example of fire-generated landscape mosaic that enhance regional diversity (Dantas, Batalha, \& Pausas, 2013; Dantas et al., 2016). For instance, savannas and forests harbour different species, and fires generates savanna-forest mosaics with high regional diversity; and these fire-driven vegetation mosaics are not restricted to tropical ecosystems (Pausas, 2015b). There are regions with climatic conditions that could potentially have forests, but they have biodiversity-rich savannas maintained by fires (Bond \& Parr, 2010). With our data, we cannotassess the relative role of selective processes versus the coexistence in landscape mosaics, but both processes are likely to be important. In fact, the two processes are linked, as landscape mosaics are an appropriate framework for population divergences and selective processes in fire-prone ecosystems (Castellanos, Gonzålez-Martínez, \& Pausas, 2015; Pausas, 2015b; Simon et al., 2009; Talluto \& Benkman, 2013); that is, our results suggest that fire generates the appropriate conditions for a large variety of plants in many regions worldwide. Furthermore, animal diversity is also enhanced by landscape mosaics (Bond \& Parr, 2010; Bowman et al., 2016; Law \& Dickman, 1998; Ponisio et al., 2016), because different plant communities generate diferent niches for fauna (Hutchinson, 1957; MacArthur \&MacArthur, 1961; Stevens \& Tello, 2011) and opportunities for species interactions (Janz, Nylin, \&Wahlberg, 2006; Ponisio et al., 2016). 
Thus, fire regime is also likely to be associated with animal and total diversity at the global scale, although further research is needed.

Global remote sensing tools with thermal sensors (e.g., MODIS) provided a magnificent and unprecedented view of the importance of fires at the global scale ('the fire overview effect'). These tools have been used mainly for studying fire regimes and estimating fire emissions at the global scale (Archibald et al., 2013 ; van derWerf et al., 2010). Here, we combine this technology with global species richness data to provide first global assessment of the importance of fire as a major determinant of species diversity. Fires delay competitive exclusion, increase landscape heterogeneity and generate new niches for a diversity of species. Although the response to fire at the local scale varies among biomes and ecosystems, a world without fires would probably be less diverse. Previous research emphasized the importance of environmental factors related to the water-energy balance (e.g., Francis \& Currie 2003; Hawkins et al., 2003; O’Brien, 2006) to explain global diversity. Our results do not deny the importance of these parameters but suggest that fire regime may have been overlooked when interpreting global diversity patterns, as it is a driver generating temporal and spatial variability; that is, fire needs to be considered to understand not only global ecosystem distributions (Bond et al., 2005), but also their diversity.

\section{ACKNOWLEDGMENTS}

Financial support was provided by the FILAS project (CGL201564086-P) from the Spanish government (Ministerio de Economía y Competitividad) and the PROMETEO/2016/021 project from the Valencia government (Generalitat Valenciana). CIDE (Desertification Research Centre) is a joint institute of the Spanish National Research Council (CSIC), the University of Valencia and Generalitat Valenciana. We declare no conflict of interest.

\section{DATA ACCESSIBILITY}

Remote sensing data aggregated at the ecoregion scale and shapefiles of the maps are available at https://doi.org/10.6084/m9.figshare.4579162

\section{REFERENCES}

Adams, J. M., \& Woodward, F. I. (1989). Patterns in tree species richness as a test of the glacial extinction hypothesis. Nature, 339, 699-701.

Archibald, S., Lehmann, C. E. R., Gömez-Dans, J. L., \& Bradstock, R. A. (2013). Defining pyromes and global syndromes of fire regimes. Proceedings of the National Academy of Sciences USA, 110, 6442-6447.

Bird, R. B., Bird, D. W., Codding, B. F., Parker, C. H., \& Jones, J. H. (2008). The "fire stick farming" hypothesis: Australian Aboriginal foraging strategies, biodiversity, and anthropogenic fire mosaics. Proceedings of the National Academy of Sciences USA, 105, 1479614801.

Bjornstad, O. N. (2009). ncf: spatial nonparametric covariance functions. $\mathrm{R}$ package version 1.1-3. URL: http://CRAN.R-project.org/ package5ncf.
Bond, W. J., \& Keeley, J. E. (2005). Fire as a global 'herbivore': The ecology and evolution of flammable ecosystems. Trends in Ecology and Evolution, 20, 387-394.

Bond, W.J., \& Parr, C. L. (2010). Beyond the forest edge: Ecology, diversity and conservation of the grassy biomes. Biological Conservation, 143, 2395-2404.

Bond, W. J., Woodward, F. I., \& Midgley, G. F. (2005). The global distribution of ecosystems in a world without fire. New Phytologist, 165, 525-538.

Bowman, D. M. J. S., Balch, J., Artaxo, P., Bond, W. J., Cochrane, M. A., D'Antonio, C. M., ... Krawchuk, M. A. (2011). The human dimension of fire regimes on Earth. Journal of Biogeography, 38, 2223-2236.

Bowman, D. M. J. S., Perry, G. L. W., Higgins, S. I., Johnson, C. N., Fuhlendorf, S. D., \& Murphy, B. P. (2016). Pyrodiversity is the coupling of biodiversity and fire regimes in food webs. Philosophical Transactions of the Royal Society B: Biological Sciences, 371, 20150169.

Burkle, L. A., Myers, J. A., \& Belote, R. T. (2015). Wildfire disturbance and productivity as drivers of plant species diversity across spatial scales. Ecosphere, 6, 1-14.

Bytebier, B., Antonelli, A., Bellstedt, D. U., \& Linder, H. P. (2011). Estimating the age of fire in the Cape flora of South Africa from an orchid phylogeny. Proceedings of the Royal Society B: Biological Sciences, 278, 188-195.

Castellanos, M. C., Gonzălez-Martínez, S. C., \& Pausas, J. G. (2015). Field heritability of a plant adaptation to fire in heterogeneous landscapes. Molecular Ecology, 24, 5633-5642.

Charles-Dominique, T., Beckett, H., Midgley, G. F., \& Bond, W. J. (2015). Bud protection: a key trait for species sorting in a forest-savanna mosaic. New Phytologist, 207, 1052-1060.

Cohn, J. S., Di Stefano, J., Christie, F., Cheers, G., \& York, A. (2015). How do heterogeneity in vegetation types and post-fire age-classes contribute to plant diversity at the landscape scale? Forest Ecology and Management, 346, 22-30.

Coleman, B. D., Mares, M. A., Willig, M. R., \& Hsieh, Y.-H. (1982). Randomness, area, and species richness. Ecology, 63, 1121-1133.

Connell, J. H. (1978). Diversity in tropical rain forests and coral reefs. Science, 199, 1302-1310.

Crisp, M. D., Burrows, G. E., Cook, L. G., Thornhill, A. H., \& Bowman, D. M. J. S. (2011). Flammable biomes dominated by eucalypts originated at the Cretaceous-Palaeogene boundary. Nature Communications, 2, 193.

Dantas, V. L., Batalha, M. A., \& Pausas, J. G. (2013). Fire drives functional thresholds on the savanna-forest transition. Ecology, 94, 2454-2463.

Dantas, V. L., Hirota, M., Oliveira, R. S., \& Pausas, J. G. (2016). Disturbance maintains alternative biome states. Ecology Letters, 19, 12-19.

Diniz-Filho,J. A. F., Bini, L. M., \& Hawkins, B. A. (2003). Spatial autocorrelation and red herrings in geographical ecology. Global Ecology and Biogeography, 12, 53-64.

Farnsworth, L. M., Nimmo, D. G., Kelly, L. T., Bennett, A. F., \& Clarke, M. F. (2014). Does pyrodiversity beget alpha, beta or gamma diversity? A case study using reptiles from semi-arid Australia. Diversity and Distributions, 20,663-673.

Francis, A. P., \& Currie, D. J. (2003). A globally consistent richnessclimate relationship for angiosperms. The American Naturalist, 161, 523-536.

Fraser, L. H., Pither, J., Jentsch, A., Sternberg, M., Zobel, M., Askarizadeh, D., ... Zupo, T. (2015). Worldwide evidence of a unimodal relationship between productivity and plant species richness. Science, 349 , 302-305. 
Giglio, L. (2013). MODIS collection 5 active fire product user's guide. Version 2.5. College Park: Department of Geographical Sciences, University of Maryland.

Gillman, L. N., \& Wright, S. D. (2006). The influence of productivity on the species richness of plants: A critical assessment. Ecology, 87, 1234-1243.

Gillman, L. N., Wright, S. D., Cusens, J., McBride, P. D., Malhi, Y., \& Whittaker, R. J. (2015). Latitude, productivity and species richness. Global Ecology and Biogeography, 24, 107-1 17.

Gömez-Gonzălez, S., Torres-Díaz, C., Bustos-Schindler, C., \& Gianoli, E. (2011). Anthropogenic fire drives the evolution of seed traits. Proceedings of the National Academy of Sciences USA, 108, 1874318747.

Grace, J. B., Anderson, T. M., Seabloom, E. W., Borer, E. T., Adler, P. B., Harpole, W. S., ... Smith, M. D. (2016). Integrative modelling reveals mechanisms linking productivity and plant species richness. Nature, 529, 390-393.

Grime, J. P. (1973). Competitive exclusion in herbaceous vegetation. Nature, 242, 344-347.

Grime, J. P. (1979). Plant strategies and vegetation processes. New York, NY: Wiley.

Hawkins, B. A., Field, R., Cornell, H. V., Currie, D. J., Guẽgan, J. F., Kaufman, D. M., ... Turner, J. R. G. (2003). Energy, water, and broad-scale geographic patterns of species richness. Ecology, 84, 3105-3117.

He, T., Lamont, B. B., \& Downes, K. S. (2011). Banksia born to burn. New Phytologist, 191, 184-196.

He, T., Pausas, J. G., Belcher, C. M., Schwilk, D. W., \& Lamont, B. B. (2012). Fire-adapted traits of Pinus arose in the fiery Cretaceous. New Phytologist, 194, 751-759.

Hernăndez-Serrano, A., Verdủ, M., Gonzălez-Martínez, S. C., \& Pausas, J. G. (2013). Fire structures pine serotiny at different scales. American Journal of Botany, 100, 2349-2356.

Hijmans, R. J., Cameron, S. E., Parra, J. L., Jones, P. G., \& Jarvis, A. (2005). Very high resolution interpolated climate surfaces for global land areas. International Journal of Climatology, 25, 1965-1978.

Huston, M. (1979). A general hypothesis of species diversity. The American Naturalist, 113, 81-101.

Huston, M. A. (2014). Disturbance, productivity, and species diversity: Empiricism vs. logic in ecological theory. Ecology, 95, 2382-2396.

Hutchinson, G. E. (1 957). Concluding remarks. Cold Spring Harbor Symposia on Quantitative Biology, 22, 415-427.

Janz, N., Nylin, S., \& Wahlberg, N. (2006). Diversity begets diversity: Host expansions and the diversification of plant-feeding insects. $B M C$ Evolutionary Biology, 6, 1-10.

Kaufman, Y. J., Justice, C. O., Flynn, L. P., Kendall, J. D., Prins, E. M., Giglio, L., ... Setzer, A. W. (1988). Potential global fire monitoring from EOS-MODIS. Journal of Geophysical Research, 103, 3221532238.

Keeley, J. E., Bond, W. J., Bradstock, R. A., Pausas, J. G., \& Rundel, P. W. (2012). Fire in Mediterranean ecosystems: Ecology, evolution and management. Cambridge, U.K.: Cambridge University Press.

Keeley, J. E., Pausas, J. G., Rundel, P. W., Bond, W. J., \& Bradstock, R. A. (2011). Fire as an evolutionary pressure shaping plant traits. Trends in Plant Science, 16, 406-411.

Keeley,J.E., \& Rundel, P. W. (2005). Fire and the Miocene expansion of C4 grasslands. Ecology Letters, 8, 683-690.

Kelly, L. T., Nimmo, D. G., Spence-Bailey, L. M., Taylor, R. S., Watson, S. J., Clarke, M. F., \& Bennett, A. F. (2012). Managing fire mosaics for small mammal conservation: A landscape perspective. Journal of Applied Ecology, 49, 412-421.

Kier, G., Mutke, J., Dinerstein, E., Ricketts, T. H., Kєiper, W., Kreft, H., \& Barthlott, W. (2005). Global patterns of plant diversity and floristic knowledge. Journal of Biogeography, 32, 1107-1116.

Krawchuk, M. A., Moritz, M. A., Parisien, M.-A., Van Dorn,J., \& Hayhoe, K. (2009). Global pyrogeography: the current and future distribution of wildfire. PLoS One, 4, e51 02.

Kreft, H., \&Jetz, W. (2007). Global patterns and determinants of vascular plant diversity. Proceedings of the National Academy of Sciences USA, 104, 5925-5930.

Law, B. S., \& Dickman, C. R. (1998). The use of habitat mosaics by terrestrial vertebrate fauna: Implications for conservation and management. Biodiversity \& Conservation, 7, 323-333.

Legendre, P. (1993). Spatial autocorrelation: Trouble or new paradigm? Ecology, 74, 1659-1673.

Lennon, J. J. (2000). Red-shifts and red herrings in geographical ecology. Ecography, 23, 101-113.

Littell, J. S., McKenzie, D., Peterson, D. L., \& Westerling, A. L. (2009). Climate and wildfire area burned in western US ecoprovinces, 19162003. Ecological Applications, 19, 1003-1021.

Loucks, O. L. (1970). Evolution of diversity, efficiency, and community stability. American Zoologist, 10, 17-25.

MacArthur, R. H., \& MacArthur, J. W. (1961). On bird species diversity. Ecology, 42, 594-598.

Mackey, R. L., \& Currie, D. J. (2001). The diversity-disturbance relationship: Is it generally strong and peaked? Ecology, 82, 3479.

Marlon, J. R., Bartlein, P. J., Carcaillet, C., Gavin, D. G., Harrison, S. P., Higuera, P. E., ... Prentice, I. C. (2008). Climate and human influences on global biomass burning over the past two millennia. Nature Geoscience, 1,697-702.

Martin, R. E., \& Sapsis, D. B. (1992). Fires as agents of biodiversity: Pyrodiversity promotes biodiversity. In H.M. Kerner (Ed.), Proceedings of the conference on biodiversity of northwest California, 1991 (pp. 150157). Berkeley, CA: University of California.

Naeem, S., Thompson, L. J., Lawler, S. P., Lawton, J. H., \& Woodfin, R. M. (1994). Declining biodiversity can alter the performance of ecosystems. Nature, 368, 734-737.

O’Brien, E. M. (2006). Biological relativity to water-energy dynamics. Journal of Biogeography, 33, 1868-1888.

Olson, M., Dinerstein, E., Wikramanayake, E., Burgess, N. D., Powell, G. V., Underwood, E. C., ... Loucks, C. J. (2001). Terrestrial ecoregions of the world: A new map of life on earth. Bioscience, 51, 933-938.

Parisien, M. A., \& Moritz, M. A. (2009). Environmental controls on the distribution of wildfire at multiple spatial scales. Ecological Monographs, 79, 127-154.

Parr, C. L., \& Brockett, B. H. (1999). Patch-mosaic burning: A new paradigm for savanna fire management in protected areas? Koedoe, 42 , 1610-1619.

Pausas, J. G. (2015a). Alternative fire-driven vegetation states. Journal of Vegetation Science, 26, 4-6.

Pausas, J. G. (2015b). Evolutionary fire ecology: lessons learned from pines. Trends in Plant Science, 20, 31 8-324.

Pausas, J. G., Alessio, G. A., Moreira, B., \& Corcobado, G. (2012). Fires enhance flammability in Ulex parviflorus. New Phytologist, 193, 18-23.

Pausas, J. G., Carreras, J., Ferrę, A., \& Font, X. (2003). Coarse-scale plant species richness in relation to environmental heterogeneity. Journal of Vegetation Science, 14, 661-668. 
Pausas, J. G., \& Keeley, J. E. (2009). A burning story: The role of fire in the history of life. BioScience, 59, 593-601.

Pausas, J. G., \& Keeley, J. E. (2014). Abrupt climate-independent fire regime changes. Ecosystems, 17, 1109-1120.

Pausas, J. G., \& Paula, S. (2012). Fuel shapes the fire-climate relationship: Evidence from Mediterranean ecosystems. Global Ecology and Biogeography, 21, 1074-1082.

Pausas, J. G., \& Ribeiro, E. (2013). The global fire-productivity relationship. Global Ecology and Biogeography, 22, 728-736.

Pettorelli, N., Vik, J. O., Mysterud, A., Gaillard, J.-M., Tucker, C. J., \& Stenseth, N. C. (2005). Using the satellite-derived NDVI to assess ecological responses to environmental change. Trends in Ecology \& Evolution, 20, 503-510.

Pinheiro, J., Bates, D., DebRoy, S., Sarkar, D. \& R Core Team. (2016). nlme: Linear and nonlinear mixed effects models. R package version 3.1-128. http://CRAN.R-project.org/package5nlme.

Ponisio, L. C., Wilkin, K., M'Gonigle, L. K., Kulhanek, K., Cook, L., Thorp, R., ... Kremen, C. (2016). Pyrodiversity begets plant-pollinator community diversity. Global Change Biology, 22, 1795-1808. DOI: $10.1111 / \mathrm{gcb} .13236$.

Qian, H., \& Ricklefs, R. E. (1 999). A comparison of the taxonomic richness of vascular plants in China and the United States. The American Naturalist, 154, 160-181.

Rahbek, C., \& Graves, G. R. (2001). Multiscale assessment of patterns of avian species richness. Proceedings of the National Academy of Sciences USA, 98, 4534-4539.

Ricklefs, R. E. (1987). Community diversity: Relative roles of local and regional processes. Science, 235, 167-171.

Ricklefs, R. E., Latham, R. E., \& Qian, H. (1999). Global patterns of tree species richness in moist forests: Distinguishing ecological influences and historical contingency. Oikos, 86, 369-373.

Rosenzweig, M. L. (1995). Species diversity in space and time. Cambridge, U.K.: Cambridge University Press.

Sauquet, H., Weston, P. H., Anderson, C. L., Barker, N. P., Cantrill, D.J., Mast, A. R., \& Savolainen, V. (2009). Contrasted patterns of hyperdiversification in Mediterranean hotspots. Proceedings of the National Academy of Sciences USA, 106, 221-226.

Schroeder, W., Csiszar, I., \& Morisette, J. (2008). Quantifying the impact of cloud obscuration on remote sensing of active fires in the Brazilian Amazon. Remote Sensing of Environment, 112, 456-470.

Simon, M., Grether, R., De Queiroz, L., Skema, C., Pennington, R., \& Hughes, C. (2009). Recent assembly of the Cerrado, a neotropical plant diversity hotspot, by in situ evolution of adaptations to fire. Proceedings of the National Academy of Sciences USA, 106, 2035920364.

Stein, A., Gerstner, K., \& Kreft, H. (2014). Environmental heterogeneity as a universal driver of species richness across taxa, biomes and spatial scales. Ecology Letters, 17, 866-880.

Stevens, R. D., \& Tello,J. S. (2011). Diversity begets diversity: Relative roles of structural and resource heterogeneity in determining rodent community structure. Journal of Mammalogy, 92, 387-395.
Talluto, M., \& Benkman, C. W. (2013). Landscape-scale eco-evolutionary dynamics: Selection by seed predators and fire determine a major reproductive strategy. Ecology, 94, 1307-1316.

Tredennick, A. T., Adler, P. B., Grace, J. B., Harpole, W. S., Borer, E. T., Seabloom, E.W., ... Buckley, Y. M. (2016). Comment on "Worldwide evidence of a unimodal relationship between productivity and plant species richness". Science, 351, 457.

van der Werf, G. R., Randerson, J. T., Giglio, L., Collatz, G., Mu, M., Kasibhatla, P. S., ... van Leeuwen, T. T. (2010). Global fire emissions and the contribution of deforestation, savanna, forest, agricultural, and peat fires (1997-2009). Atmospheric Chemistry and Physics, 10, 11707-11735.

Vandvik, V., T6pper, J. P., Cook, Z., Daws, M. I., Heegaard, E., Måren, I. E., \& Velle, L. G. (2014). Management-driven evolution in a domesticated ecosystem. Biology Letters, 10, 20131082.

Verdủ, M., \& Pausas, J. G. (2007). Fire drives phylogenetic clustering in Mediterranean Basin woody plant communities. Journal of Ecology, 95, 1316-1323.

Wooster, M.J., Zhukov, B., \& Oertel, D. (2003). Fire radiative energy for quantitative study of biomass burning: Derivation from the BIRD experimental satellite and comparison to MODIS fire products. Remote Sensing of Environment, 86, 83-107.

\section{BIOSKETCHES}

JuLI G. PAUSAS is a a research ecologist at the Centro de Investigaciön sobre Desertificaciön of the Spanish National Research Council in Valencia (CIDE, CSIC). His research focuses on understanding the role of fire in nature, including studies at the different organizing levels, such as populations, species (e.g., fire-persistent traits), communities (e.g., assembly processes), landscapes and biomes.

ELOI RIBEIRO is a geoinformatician working at the International Soil Reference and Information Centre (ISRIC)-World Soil Information at Wageningen University and Research Centre (The Netherlands). He specializes in the management of databases and geographical information systems. 